\title{
Article
}

\section{A critical commentary on management science in relation to reforms after institutional National Health Service failures}

Regan, Paul John and Ball, Elaine

Available at http://clok.uclan.ac.uk/16698/

Regan, Paul John and Ball, Elaine (2017) A critical commentary on management science in relation to reforms after institutional National Health Service failures. Journal of Nursing Management, 25 (2). pp. 149-156. ISSN 0966-0429

It is advisable to refer to the publisher's version if you intend to cite from the work. http://dx.doi.org/10.1111/jonm.12425

For more information about UCLan's research in this area go to http://www.uclan.ac.uk/researchgroups/ and search for <name of research Group>.

For information about Research generally at UCLan please go to http://www.uclan.ac.uk/research/

All outputs in CLoK are protected by Intellectual Property Rights law, including Copyright law. Copyright, IPR and Moral Rights for the works on this site are retained by the individual authors and/or other copyright owners. Terms and conditions for use of this material are defined in the policies page. 


\section{A critical commentary on management science in relation to reforms following institutional National Health Service failures}

\section{Abstract}

Aim(s): A discussion paper on the United Kingdom (UK) National Health Service (NHS) market reforms. Background: NHS market reforms reliance on management science methods introduced a fundamental shift in measuring care for commissioning purposes Evaluation: A number of key reports are discussed in relation to NHS market reforms and management science. Key issues; NHS market reforms were influenced through a close alliance between policy makers, the department of health, free market think tanks and management consultancies. The timing of reforms coincided with reports on NHS failings and the evolution of measurement methods to focus on finance. Conclusions: The balance in favour of measurement practises is of concern. Management science methods are criticised in the Francis report yet promoted as the solution to some of the key findings; why may be explained by the close alliance. Implications for Nursing Management: A return to principles of management involving consensus, trust, involvement in which a shared vision and a can do, hands on approach to management and use management science methods to this end.

\section{Aims}

This discussion paper discusses UK NHS market reforms operationalised through management science. Separately, NHS market reforms and management science are contentious but in combination they appear to coincide with a period of unprecedented NHS 
failings (Tallis and Davis, 2015; see figure 1). We suggest this is not a coincidence but symptomatic of the modus operandi to manage and measure.

\section{Background}

We disclaim the right to scrutinise other countries' institutional healthcare failings, and therefore maintained a local critique; in particular, the key policy documentation responding to failures both culturally and institutionally within UK hospitals. To that effect, a literature search was undertaken of the documents written by the department of health which are deemed policy, and subsequent peer reviewed commentary on those findings. While this paper is limited to the UK, it does make significant reference to management science and its manifestation globally.

The NHS market reforms and management science started over thirty years ago with the Griffiths Management Inquiry in 1983 (DHSS, 1983). The report commissioned by the UK government was a root and branch evaluation of the NHS aimed at challenging resistance to change, and to modernise the health service (Gorsky, 2013). This led to the NHS moving away from consensus management and accepting general management with a clear chain of accountability (Fielden, 2015; Gorsky, 2013). The report included a realistic perception of the NHS by staff and the public; cost efficiency, evaluation of services, information gathering and performance management were recommended (DHSS, 1983). Critics suggested Griffiths introduced concepts from industry such as outsourcing, reducing the amount of people making and implementing decisions; resulting in the development of a costly administrative system to organise external decision making (Gorsky, 2013). Such criticisms were not 
restricted to the UK as multiple healthcare arenas internationally were driven by similar cost administration drives. Griffiths' report conceded that business in management terms realised the NHS was not profit driven and its goals should be seen in the wider social context, which could not be measured (DHSS, 1983). Griffiths also suggested the social impact of the NHS was overstated and the government of the day was urging a review of the NHS in terms of levels of service, performance measured against quality criteria, budgets, cost efficiency and productivity (DHSS, 1983). In contrast, United States healthcare was predicated on a business model which conflicted, quite radically, with the UK's post-war provision of free healthcare for all. This was the start of the management revolution along United States (US) business lines and a weakening of the social context of the NHS (Klein, 2006).

\section{Evaluation}

A precursor to the global financial crisis of 2007/8 was the introduction of a number of policy documents. In the UK this took the form of tendering competition and services such as Transforming Community Services (TCS, DH, 2009), Equity and Excellence (DH, 2010a) and Achieving world class productivity in the NHS 2009/10 2013/14 (DH, 2010b). The documents argued strongly for a market solution to funding the NHS and to distance the government from its responsibility to ensure a comprehensive healthcare system for UK taxpayers (Tallis and Davis, 2013). This distance would be achieved by what Sandel (2009, p. 4) called "markets mimicking governance". Nearly a decade later, there is a speculative NHS where movements in financial markets aggregate healthcare expenditure and provision. The Health and Social Care Act (2012) brought into sharp focus market liberalisation and a publically owned NHS with a shift towards a US model of health care (Tallis and Davis, 2013). The Act (2012) was clarified operationally in The National Health Service (Procurement, patient 
choice and competition) Regulations (2013) to meet the needs of NHS patients, and improve quality and efficiency through contracts and competition (part 2, 2, p.2). The NHS has therefore evolved to manage the expansion of procurement which is promoted as the solution to saving public money, increasing productivity and competition between NHS and non-NHS providers by the methods of management science (Krachler and Greer, 2015).

Money saving initiatives are not limited to a country or an economic crisis and even when bear and bullish markets and struggling economies level out, cost-saving efficiencies extend interminably (Maresso et al., 2015). Indeed, anti-austerity has turned into a global movement in which media commonly report thousands of people taking to the streets in countries like Greece, Portugal and Ireland to name a few. How much statutory healthcare is being eroded by the erratic speculation of earlier market turbulence is disputable. However, European-wide case studies on austerity and healthcare by Maresso et al (2015) and the Kings Fund are in no doubt of the collision between performance-efficiency and cost-efficiency when financial markets go into crisis. Being asked to do more for less and with less is common parlance. The "unprecedented slowdown" in the NHS since 2010 has been well documented by the Kings' Fund locally (Appleby 2014). Internationally, Deloitte's reported in its 2015 Global Healthcare Outlook that most world economies face formidable challenges in healthcare provision with spending hitting $2 \% .10 .6 \%$ of growth domestic product means that as demands rise with population, living longer, early diagnoses, innovations etc, healthcare systems worldwide face significant challenges ahead. Yet, with hindsight come the measures, and, as empirical as they may be, always seems to include ways to save money; or as the discourse might say, to demonstrate values in a competing economic world. 
Key issues

We are not arguing against science or an evidence-base, but the balance in favour of measurement practises: that in itself is not a science, but an activity and one we examine critically as a key issue and cause for concern linked to NHS cultural and institutional failings. Management consultancies reports, commissioned by the department of health, are discussed alongside the proliferation of management science (whatever that codicil implies).

Management science principles, developed by Frederick Taylor (1856-1915) in the US, refer to the analysis of workload through technocratic, procedural practises with the specific aim of increasing efficiency and productivity (Gupta and Bennett, 2014). Proponents are taught how to measure human action through quantitative methods used as benchmarks to control quality and productivity (Caldari, 2007). The Taylorist methods went out of favour in the middle of the twentieth century due to the negative effect of work intensification, lowered worker moral, the increased ratio of managers to workers and sharper procedural focus (Caldari, 2007). Management science resurfaced in the mid-twentieth century in Harvard University's Masters in Business Administration (MBA) proposing Neo-Taylorist principles as the antidote to organisational problems (Axelson, 1998). Management science methods promote decision making based on a scientific repository of information to shape policy (Siedelman, 2015). However, the quantitative methods were criticised as pseudo-scientific because unless individuals are trained in such methods, the process is difficult to question (Caldari, 2007).

\section{The proliferation of management practices}

The quantification of human activity using information to inform business decision making has been adopted by international companies such as NASA, IBM, Kellogg's, BMW, Nokia, Samsung, Proctor and Gamble and Ford to name a few (Anderson et al., 2009). US style 
management science methods are now so prevalent they are applied in a variety of ways internationally such as data mining, resource distribution and forecasting, financial logistics, quality assurance, networks (inter connected group or system), optimisation (looking for the best), project planning and management, queuing, simulation and experimentation (Anderson et al., 2009); in other words, an array of management-science-information to advise business decision making has proliferated. Management science methods are also attractive to politicians. For example, the UK department of health utilised McKinsey and company (DH, 2010b) to review NHS commissioning. The same company was commissioned to review Northern Ireland social work education in 2004 (DHSSPS, 2004); the general management that Griffiths reasonably suggested had evolved to influence national policy and organisational discourse. Whether or not companies such as this are inside or outside an organisation is debatable; it is sometimes difficult to say if commissioned bodies are external and employed to improve productivity or function or simply come in to stream-line a business and then leave. Either way, external influences are often viewed with suspicion and much has been written in recent years about adapting companies to fit with market conditions at the exclusion of tradition or company philosophy. Lean management is a way of enhancing while also preserving company values. Influence from outside is regarded by lean management as "waste" as employees within the organisation are more than capable of identifying issues to both locate and improve functionality if invited.

Despite a plethora of organisational theories since Taylor, as a discussion paper, we use the term "management science" to refer to the adoption of neo-Taylorist quantification methods promoting organisational efficiency and labour productivity (Axelson, 1998; Gupta and Bennett, 2014). Proponents range from external companies with little or no experience in the sector they manage or a hybridisation of experienced practitioners managing clinical areas 
using management science methods (Fulop 2012). Management science was extended in the NHS to manage productivity and market reforms and the collaboration of NHS market reforms and management science created systems to manage functionality through standards, benchmarks, guidelines and decision models with criticism of the effectiveness of measurement based assessment effectiveness (Beaussier et al, 2015). The tendency to create systems promotes the myth of productivity - doing more work with less staff - and dependency on procedural systems (Appleby et al., 2015). Performance indicators identified in policy-led management inevitably reduce local decision making based on local data (Appleby et al, 2015) and promote a dependency on risk based models rather than practitioner autonomy (Beaussier et al, 2015). As lean management espouses, this rules out potential that could be tapped into within an organisation from employees who deal with functional issues, snags and bottlenecks on a daily basis. This type of tension is described as "muda" by lean management (or waste). By encapsulating many of the principles of lean management, employees within an organisation are not legitimised by proponents from outside an organisation; rather their motivation, potential and investment in the organisation is stymied.

In contrast to lean management, management science promotes a breed of technocrats in organisations to increase bureaucratic control. They are people not trained to provide healthcare and are management consultants, risk managers and accountants who bring with them new tiers of obstruction (Hopper and Hopper, 2009). Moreover, despite healthcare institutions employing their own clinicians to become managers, there is evidence they become de-skilled when balancing the need to be change agents, diplomatic administrators and entrepreneurs while attempting to meet government policy-led targets (Gatenby et al., 2015). For many, the restrictions of policy-led management stifle their judgement to manage 
local issues flexibly and they may purposefully resist strategic objectives (Gatenby et al, 2014).

\section{Management consultancy and the McKinsey report}

Management science practise is a blunt instrument incentivised by its own intrinsic design to measure, data crunch and cut to the bone (Hopper and Hopper, 2009). While this is vigorous statement, examples can be found in reports with questionable meta-narratives where management science dictates rather than proposes (which is not the basis of science as an endeavour or discipline). One example is the aforementioned McKinsey report (DH, 2010b) which was a feasibility study for the department of health on how commissioners could increase productivity in the NHS. Notably McKinsey is a US consultancy giant with at least ninety clients in Fortune magazine's top one hundred corporations and perhaps an unlikely choice considering the pick of unbiased academic analysis available (Tallis and Davis, 2015). However, the report identified outcomes based on current predictions to "calculate current spend assuming that productivity improvements identified ... have been achieved" (DH, 2010b): an example surely of data fitting an agenda proposed as a possible solution (Tallis and Davis, 2013). If we are to assume that the recommendations of the McKinsey report were acted upon, might explain how a system can be purposefully designed to be in a permanent state of tension, not harmony, as seen in the various reports of NHS failures with the solution already identified to promote more measurement and market liberalisation (Berwick, 2013; Cloward-Piven, 1966).

The McKinsey report (DH, 2010b) identified a close working relationship between UK policy makers at the department of health and influential US management consultancies, think tanks and regulatory bodies (Tallis and Davis, 2013). For example, the then head of strategy for the 
department of health became a partner at McKinsey and was instrumental in the two "Darzi" reports; a former McKinsey partner was later in an influential position in Monitor, the hospital regulators, the Nuffield Trust and The Kings Fund (Tallis and Davis, 2013, p. 60). We mention the close working relationship between commissioned consultancies and the possibility of vested interest of both parties agenda. One example of the agenda behind the McKinsey report (DH, 2010b) was to suggest reducing mandatory staffing levels which had been considered important to maintain the protection of the public. However, it also served to overcome what McKinsey referred to as resistance and "pain" to the workforce of market reforms (DH, 2010b, p. 84).

\section{The Munro report}

We could argue that no one - be they employee or patient, adult or child - is immune. In the UK the Munro review of child protection (DfE, 2011) commissioned by the secretary of State for Education asked the question "what helps professionals make the best judgments they can to protect a vulnerable child?" In short, previous versions of the report had identified that the child protection system had become "...over over-bureaucratised and focused on compliance to one that values and develops professional expertise..." (p. 6). This was due to the emphasis on performance indicators which provided a small part of the overall picture to reinforce "process" over effective help and support given to children (DfE, 2011). The development of an overtly defensive system of prescriptive procedures and recording systems for health visitors was found to obstruct decision making ability and services developing support and expertise to work effectively with children and families (DfE, 2009, p. 6). Instead of "doing things right" the service should instead "do the right thing" to check children and families were being helped. In short, the system should value professional expertise for the benefit of the child and family rather than stifle timely decision making (DfE, 2011). 
Performance indicators and targets are therefore clearly flawed methods of control yet remain the modus operandi for policy-led management science (DfE, 2011). With this conclusion in mind we now discuss another report which made similar observations but with different conclusions, the Francis report.

In the UK in the wake of the 2013 Mid Staffordshire inquiry (commonly referred to as the Francis report) and the two hundred and ninety recommendations, the government announced a number of patient safety initiatives with fifteen locally led collaborative groups covering the geography of England with the aim of making the NHS the safest healthcare system in the world (Berwick, 2013). Berwick's report entitled A promise to learn (2013) suggested it "...is the systems, procedures, conditions, environment and constraints they face that lead to patient safety problems..." Therefore, according to the report, staff in the NHS were considered blameless to a large extent, in the majority of cases, and in order to learn from the mistakes he suggested the NHS should be a learning organisation (p.4). Berwick suggests patients should come first and the "...quantitative targets should be used with caution. Such goals do have an important role en route to progress, but should never displace the primary goal of better care...transparency..." (Berwick, 2013, p. 4). However, there is little or no criticism of NHS market reforms and the business culture that led to an attitudinal change leading to neglect. Notably, in the Francis report staff and patients' complaints were ignored as were the statistics indicating high mortality rates in comparison to others in England (Berwick, 2013: Beaussier et al 2015). Berwick's recommendations, however, suggest the mastery of quality and patient safety science, continual improvement, supported change and supervisory/ regulatory systems be made simpler to avoid diffusion of responsibility (Berwick, 2013). Berwick also suggested a need for transparency, data sharing 
in a timely fashion, patients and their carers having a voice, an appropriate number of staff and learning from mistakes. The report also suggests:

"commissioners, regulators and providers of training and education for healthcare professionals ... should ensure that all healthcare professionals receive ... education on the principles and practices of patient safety, on measurement of quality and patient safety, and on skills for engaging patients actively" (p. 26).

What is noticeable is that Berwick's (2013) suggestions to improve measurement skills across the board, from chief executive to staff, were adapted from the US healthcare conglomerate Kaiser Permanente (KPMG). The recommendations go further to state most providers do not have the capacity to analyse, monitor, or learn from safety and quality information (Berwick, 2013).

Hence, rather than be critical of a quantitative measurement culture, Berwick actually is promoting the expansion of data management even further (Berwick, 2013). Berwick's conclusions are contradicted by Beaussier et al's (2015, p.2) research into the value of measurement based approaches, in relation to the rise of quantification methods in the NHS, and its aim to regulate, improve clinical effectiveness and proportionality of decision making. Through "better regulation," standard setting, gathering of information, management science aims to effectively ensure a risk approach to probability and consequences through measurable outcome based assessment (Demeritt et al., 2015). However, criticism of measurement outcomes are their timeliness, interpretation, variety of indicators, tolerance for error and political choice in relation to target setting. For example, there is a tendency to 
identify targets that have public appeal in relation to high mortality (Demeritt et al, 2007). Beaussier et al (2015) concludes that measurement based assessment have failed to improve the quality of the NHS service provision because of the lack of consensus about what quality of care actually means and how it can be achieved against the mantra of productivity and efficiency.

The further development of measurement practice is of concern because it indicates a confidence in practises which are significant factors in reports on the failing of the NHS (DH, 2012), see figure 1 below, such as the parliamentary ombudsman report entitled Care and compassion (2011) and The Morecambe bay investigation (2015), symptomatic in part because of their timing in relation to NHS market reforms and the expansion of management science within the NHS since 2010 (Holme, 2015).

\section{Figure 1: Reports, timings and conclusions}

\begin{tabular}{|l|l|l|}
\hline Reports & Timings & Conclusions \\
\hline $\begin{array}{l}\text { The Parliamentary } \\
\text { and Health Service } \\
\text { Ombudsman Care } \\
\text { and Compassion } \\
(2011)\end{array}$ & $2009-2010$ & $\begin{array}{l}\text { Ten cases involving elderly people affected by poor } \\
\text { communication, poor discharge planning, indifference, } \\
\text { neglect of basic needs, people left in soiled clothing/ } \\
\text { bedding, unwashed, unfed, thirsty, wishes were ignored, } \\
\text { lack of compassion. The report identifies institutional } \\
\text { attitudes, a failure to respond with compassion and } \\
\text { professionalism }\end{array}$ \\
\hline $\begin{array}{l}\text { The Mid } \\
\text { Staffordshire }\end{array}$ & $2005-2008$ & $\begin{array}{l}\text { A harmful cult of management since 2001 obsessed with } \\
\text { ill-considered targets, a culture of bullying and harassment } \\
\text { preventing staff from raising clinical concerns, a culture of } \\
\text { collusion and a failure to ensure essential care to patients }\end{array}$ \\
\hline $\begin{array}{l}\text { The Morecambe } \\
\text { Bay Investigation } \\
\text { (2015) }\end{array}$ & $2004-2013$ & $\begin{array}{l}\text { A major factor affecting clinical failings and high } \\
\text { neonatal, maternal mortality rates was a need to save } £ 24 \\
\text { million from the Trusts budget (p.59) }\end{array}$ \\
\hline
\end{tabular}

The government's response to the Francis report's two hundred and ninety recommendations is thorough, costly and comprehensive (DH 2015) but then again such reports may not have 
been warranted if such cultural shifts and commissioning reforms had been more moderate. This assertion is made in the knowledge that since its inception in 1948, apart from NHS reports from the late sixties (Cochrane, 1990; Robb, 1967), the main point is that at no time in the history of the NHS have so many reports occurred in such a short time (Holme, 2015). This leads to a tentative conclusion that management science has impacted on the NHS and a degree of caution is required if suggesting it is part of the solution to Berwick (2013) and NHS England's (2015) responses to the Francis inquiry.

Future proofing a learning organisation

The NHS England (2013) and Berwick's (2013) recommendations to empower staff, ensure transparency and increase measurement of action using data systems appears to be at odds with the need for professionals to use their judgement unobstructed by systems management. These inconsistencies mean findings identifying what can be learnt do not take into consideration the wider context, such as why there are reports of failings in the NHS now more than at any other point in the history of the NHS and what are the significant factors (Holme, 2015).

\section{A return to common sense and a shared vision}

We now discuss the implications for nursing management through Hopper and Hopper's (2009) antidote to the proliferation of management science methods and its attitudes. Hopper and Hopper (2009) suggest an antidote to management science would be to let expert healthcare practitioners be empowered to make the necessary changes in clinical practice based on their motivation for personal responsibility, expertise and autonomy. Hopper and Hopper (2009) suggest a return to principles of management that involve consensus, trust, 
great teamwork, a clear leadership and having a shared vision. They referred these principles to the Puritan values of the US founding fathers. Trusting practitioner to be responsible for their actions was a finding in the Munro report (DfE, 2011), Berwick (2013) and NHS England (2013). Hopper and Hopper (2009) identified that innovation with a "hands on" and "can do" workforce "leading from the front" are the possible solution to the disconnect between the collection of data and its application. Then change can be local, achievable and above all not policy-led. Critically for nurse managers, Hopper and Hopper (2009) suggest that sustainable innovation starts with and should be implemented by the same expert people who then evaluate its effect. This approach led them to quote Cameron (1963), often attributed to Einstein because it was a sign hanging on his office door at Princeton University, that "...not everything that can be counted counts and not everything that counts can be counted..." (Cameron, 1963, p. 13). The antithesis of this is manifested in the McKinsey report (DH, 201b, p.111) and a cost effective conclusion to "...stop/reduce procedures with no/limited clinical benefit...." Hence, the moral impact of management science who decide what is of clinical benefit. The nurse manager is instrumental at ward level in correcting such attitudes by valuing and promoting the qualitative aspects of care.

Not everything that counts can be counted

Related to the Francis report and Berwick (2013) is the Druckerian (1993) idea that “... you can't measure what you can't manage..." and, by extension, proponents of such a system may come to think “...if it can't be measured it doesn't exist..." (Hopper and Hopper, 2009, p. 133). Hence, the focus on quantifying human action inevitably leads to dehumanised inaction, as seen in the findings of the Francis report. The moral premise underlying the notion "not everything that counts can be counted" is a sense of generosity and common 
purpose, putting patients first and a share of social goods such as education, the law, healthcare and a stable society (Ricoeur, 2000). Griffiths appeared to accept this to a certain extent (DHSS, 1983). These are the social bonds that tie the rights of the individual through the collective power of citizens (Ricoeur, 2000) and Tallis and Davis (2013, p. 9) quote Lord David Owen in capturing the spirit of the NHS as a: “...a vocational service. It needs to retain in it a generosity of purpose, philosophical commitment and a one-to-one relationship with the individual patient..." Many still believe these principles to be true and an NHS funded through public taxation should be solely for the benefit of society, not balancing the books, meeting targets and shareholder dividends (Tallis and Davis, 20015). We suggest therefore in this paper that this narrative has become over powering in the NHS through management science operationalising NHS market reforms based on profit and a lack of generosity.

\section{Conclusion}

This paper has discussed market reforms operationalised through management science. The Health and Social Care Act (2012) was the culmination of a thirty-year agenda to promote NHS market reforms and liberalise it through competition. We are critical of management science which is a blunt instrument if wielded without common sense and knowledge of the clinical context. The tendency of management science to control elements of clinical practice, such as decision making was discussed in the corrective findings of the Munro report (DH, 2011). The effect on healthcare coincided with reports on unprecedented failings within the NHS (see figure 1) and measurement being promoted as the reason and solution. Counting only what can be counted for commissioning purposes, expunges what really counts which is care and professional decision making unobstructed by aggregated measurement. Therefore, our observation is universal in terms of prioritising patient care where workers and their 
managers are given the capacity to seek resolutions, within their own healthcare arena, as problems occur rather than retrospectively as measurement outcomes.

\section{References}

Anderson D. R., Sweeney D. J, Williams T. A., Wisnieswki M. (2009). An introduction to management science: Quantitative approaches to decision making. Cengage Learning EMEA: London.

Appleby J., Baird B., Thompson J., Jabbal J. (2015). The NHS under the coalition government. Part two: NHS performance. http://www.kingsfund.org.uk/sites/files/kf/field/field_publication_file/the-nhs-under-thecoalition-government-nhs-performance-kings-fund-mar15.pdf.

Appleby, J., Galea, A., \& Murray, R. (2014). The NHS productivity challenge. Experience from the front line. Available at: www.kingsfund.org.uk/publications/nhs-productivitychallenge (accessed on 24 May 2016)

Axelson R. (1998). Towards an evidence-based health care management. International Journal of Health Planning and Management, 13, 307-317. doi: 10.1002/(SICI)10991751(199810/12)13:4<307::AID-HPM525>3.0.CO;2-V.

Beaussier A. L., Demeritt D., Griffiths A., Rothstein H. (2015). Why risk based quality of healthcare regulation cannot succeed. HOWSAFE working paper 5. HowSAFE: How states account for failure in Europe: Risk and the limits of governance. ESRC. 1-20.

Berwick D. (2013) A promise to learn-a commitment to act. Improving the Safety of patients in England. National Advisory Group on the Safety of Patients in England.

Caldari K. (2007.) Alfred Marshall's critical analysis of management science. Euro. J. History of Economic Thought, 14:1 55 - 78. doi: 10.1080/09672560601168405.

Cameron W. B. (1963). Informal Sociology, A casual introduction to sociological thinking. Random House, New York.

Cloward R.A., Piven F. F. (1966). The weight of the poor: A strategy to end poverty. http://freedomoutpost.com/wp-content/uploads/2014/07/61004896-The-Cloward-PivenStrategy-The-Weight-of-the-Poor-A-Strategy-to-End-Poverty-by-Cloward-Piven-pub-2-May1966.pdf.

Department of Health and Social Security (1983). NHS management inquiry. Griffiths, R. London. http://www.sochealth.co.uk/national-health-service/griffiths-report-october-1983/. 
Department of Health, Social Services and Public Safety (2004). A strategy for professional development in social work. Report on a review of the framework for post qualifying social work education in Northern Ireland. JM consulting, London.

Department of Health (2009). Transforming community services: Enabling new patterns of provision. London, HMSO.

Department of Health (2010a). Equity and excellence: Liberating the NHS. London: London, HMSO.

Department of Health (2010b). Achieving world class productivity in the NHS 2009/10 2013/14: Detailing the size of the opportunity. McKinsey and Co. http://webarchive.nationalarchives.gov.uk/20130107105354/http:/www.dh.gov.uk/prod_cons um_dh/groups/dh_digitalassets/documents/digitalasset/dh_116521.pdf.

Department of Health (2011). Health visitor implementation plan 2011-15: A call to action. https://www.gov.uk/government/uploads/system/uploads/attachment_data/file/213759/dh_12 4208.pdf.

Department of Health (2012.) Compassion in practice: Nursing, Midwifery and care staff. Our vision and strategy. https://www.england.nhs.uk/wpcontent/uploads/2012/12/compassion-in-practice.pdf

Department for Education (2011). The Munro review of child protection: Final report. A child centred system. Report by Professor Eileen Munro. Crown Copyright. https://www.gov.uk/government/uploads/system/uploads/attachment_data/file/175391/Munro -Review.pdf.

Demeritt D., Rothstein H., Beaussier A.-L., Howard M. (2015). Mobilizing risk: Explaining policy transfer in food and occupational safety regulation in the UK. Environment and Planning A, 47, 373-91. doi: 10.1068/a140085p.

Drucker P. (1993). The practice of management (Reissue edition). New York: Harper Business.

Fielden J (2015). A medical directors perspective on healthcare leadership. Future Hospital Journal, 2 (3), 190-193. doi: 10.7861/futurehosp.2-3-190.

Fulop L (2012). Leadership, clinician managers and a thing called hybridity. Journal of Health Organization and Management, 26 (5): 578-604. doi:10.1108/14777261211256927.

Gatenby M., Rees C., Truss K., Alfes K., Soane E. (2014). Managing change, or changing managers? The role of middle managers in UK public service reform. Public Management review, 17, 8, 1124-1145. DOI: 10.1080/14719037.2014.895028.

Gorsky M. (2013). 'Searching for the people in charge:' Appraising the 1983 Griffiths NHS management inquiry. Medical History, 57(1), 87-107. doi:10.1017/mdh.2012.82.

Gupta A., Bennett S. E. (2014). An empirical analysis of the effect of MBA programs on organizational success. International Journal of Educational Management, 28(4), 451- 460. 
Health and Social Care Act (2012). Number 160. Her majesty's Stationary Office http://www.legislation.gov.uk/uksi/2013/160/pdfs/uksi_20130160_en.pdf.

Hühn M. P. (2014). You reap what you sow: How MBA programs undermine ethics. Journal of Business Ethics, 121, 527 -541.

Krachler N., Greer I. (2015). When does marketisation lead to privatisation? Profit-making in English health services after the 2012 Health and Social Care Act. Social Science and Medicine, 124. 215-223. doi.org/10.1016/j.socscimed.2014.11.045.

Holme A. (2015). Why history matters to nursing. Nurse Education Today, 35, 635-637. doi: http://dx.doi.org/10.1016/j.nedt.2015.02.007.

Holmes D. (2013). Mid Staffordshire scandal highlights NHS cultural crisis. The Lancet, 381, 9866, 521-522. doi: http://dx.doi.org/10.1016/S0140-6736(13)60264-0.

Hopper K., Hopper W. (2009). The puritan gift: Re-claiming the American dream amidst global financial chaos. I.B. Tauris, London-New York.

Klein R. (2006). The new politics of the NHS: From creation to reinvention. Oxford: Radcliffe Publishing.

Maresso, A., Mladovsky, P., Thomson, S., Sagan, A., Karanikolos, M., Richardson, E., \& Kluge, H. (2015). Economic crisis, health systems and health in Europe. Country experiences. Economic crisis, health systems and health in Europe. Country experiences.

Mid Staffordshire NHS Foundation Trust Public Inquiry (2013). Report of the Mid Staffordshire NHS Foundation Trust Public Inquiry Executive summary. House of Commons. Chaired by Robert Francis, QC. Retrieved http://www.midstaffspublicinquiry.com/sites/default/files/report/Executive\%20summary.pdf.

Morecambe Bay Investigation (2015). Report of the Morecambe Bay Investigation. https://www.gov.uk/government/uploads/system/uploads/attachment_data/file/408480/47487 _MBI_Accessible_v0.1.pdf.

National Health Service, England Public Procurement, England (2013). The National Health Service (Procurement, patient choice and competition) Regulations 2013. Number 257. http://www.legislation.gov.uk/uksi/2013/257/pdfs/uksi_20130257_en.pdf.

NHS England (2013.) Towards commissioning excellence: A strategy for commissioning support services. $\quad$ https://www.england.nhs.uk/commissioning/wpcontent/uploads/sites/12/2013/06/towa-commis-exc.pdf.

Robb, B. (1967). Sans everything: A case to answer. London, Nelson.

Ricoeur P. (2000). The just. Translated by Pellauer, D. The University of Chicago Press: Chicago.

Sandel M. (2009). A new politics of the common good. Retrieved from: www.bbc.co.uk/programmes/b00lb6bt. 
Siedelman R. (2015). Disenchanted realists: Political science and the American crisis. Second Edition State University of New York Press, Albany.

Tallis R., Davies J.(2013). NHS SOS: How the NHS was betrayed - and how we can save it. One world Publications, London. 